Old Dominion University

ODU Digital Commons

Bioelectrics Publications

Frank Reidy Research Center for Bioelectrics

2001

\title{
Resonant Energy Transfer From Argon Dimers to Atomic Oxygen in Microhollow Cathode Discharges
}

\author{
M. Moselhy \\ Old Dominion University \\ R. H. Stark \\ Old Dominion University \\ K. H. Schoenbach \\ Old Dominion University \\ U. Kogelschatz \\ Old Dominion University
}

Follow this and additional works at: https://digitalcommons.odu.edu/bioelectrics_pubs

Part of the Electrical and Computer Engineering Commons, and the Inorganic Chemistry $\underline{\text { Commons }}$

\section{Repository Citation}

Moselhy, M.; Stark, R. H.; Schoenbach, K. H.; and Kogelschatz, U., "Resonant Energy Transfer From Argon Dimers to Atomic Oxygen in Microhollow Cathode Discharges" (2001). Bioelectrics Publications. 256.

https://digitalcommons.odu.edu/bioelectrics_pubs/256

\section{Original Publication Citation}

Moselhy, M., Stark, R. H., Schoenbach, K. H., \& Kogelschatz, U. (2001). Resonant energy transfer from argon dimers to atomic oxygen in microhollow cathode discharges. Applied Physics Letters, 78(7), 880-882. doi:10.1063/1.1336547

This Article is brought to you for free and open access by the Frank Reidy Research Center for Bioelectrics at ODU Digital Commons. It has been accepted for inclusion in Bioelectrics Publications by an authorized administrator of ODU Digital Commons. For more information, please contact digitalcommons@odu.edu. 


\title{
Resonant energy transfer from argon dimers to atomic oxygen in microhollow cathode discharges
}

\author{
M. Moselhy, R. H. Stark, K. H. Schoenbach, ${ }^{\text {a) }}$ and U. Kogelschatz ${ }^{\text {b) }}$ \\ Physical Electronics Research Institute, Electrical and Computer Engineering Department, \\ Old Dominion University, Norfolk, Virginia 23529
}

(Received 31 August 2000; accepted for publication 2 November 2000)

\begin{abstract}
The emission of atomic oxygen lines at 130.2 and $130.5 \mathrm{~nm}$ from a microhollow cathode discharge in argon with oxygen added indicates resonant energy transfer from argon dimers to oxygen atoms. The internal efficiency of the vacuum-ultraviolet (VUV) radiation was measured as $0.7 \%$ for a discharge in 1100 Torr argon with $0.1 \%$ oxygen added. The direct current VUV point source operates at voltages below $300 \mathrm{~V}$ and at current levels of milliamperes. (C) 2001 American Institute of Physics. [DOI: 10.1063/1.1336547]
\end{abstract}

Microhollow cathode discharges (MHCDs) are direct current, high-pressure gas discharges between perforated electrodes, separated by thin layers of dielectric. ${ }^{1}$ The diameters of the circular perforations, and the thickness of electrode foils and dielectrics are on the order of $100 \mu \mathrm{m}$. Electrons emitted from the circular cathode and accelerated in the cathode fall gain sufficient energy to excite rare gas atoms. The high-pressure operation, at and above atmospheric pressure, favors three body collisions, necessary to generate rare gas dimers. In the case of xenon they decay by emitting photons at and around $172 \mathrm{~nm}$. The internal efficiency, the ratio of optical power in the excimer emission to the electrical power required to sustain the discharge was found for xenon to be between $6 \%$ and $9 \% .^{2}$

By using rare gases with a higher atomic number, dimers can be generated in these microhollow cathode discharges, which emit at shorter wavelengths. Krypton emission peaks at $145 \mathrm{~nm}$, argon at $126 \mathrm{~nm}$, neon at $84 \mathrm{~nm}$, and helium at 74 $\mathrm{nm}$. The wavelength of xenon, krypton, and argon radiation allows the use of windows, which separate excimer source and the target of the radiation. However, since argon is relatively inexpensive, compared to xenon and krypton, and because of the fact that excimer radiation is not reabsorbed in the excimer gas, it is economical to use for argon windowless systems where source and target are in the same gas environment.

Neon and more recently helium excimer radiation from microhollow cathode discharges has been studied by Becker et $a l^{3,4}$ One of the reasons to focus on neon excimer radiation was the near-resonant transition to hydrogen. ${ }^{5}$ The energy of the excited neon atom, or neon dimer is sufficient to dissociate hydrogen and to excite the hydrogen atom to a state, which decays by emitting hydrogen Lyman- $\alpha$ and Lyman- $\beta$ radiation at 121.6 and $102.5 \mathrm{~nm}$, respectively. ${ }^{3}$ This effect proved to be very efficient, and generates a radiation, which due to its short wavelength, and small spectral width (compared to excimer emission) is considered to be a good candidate for advanced vacuum-ultraviolet (VUV) photolithography.

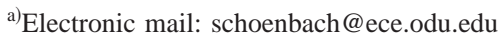

${ }^{b}$ ABB Corporate Research Ltd., Baden, Switzerland.
}

Argon excimer radiation, which is assumed to be generated at higher efficiency than neon radiation has its maximum emission at only slightly higher wavelength than the hydrogen Lyman- $\alpha$ line. First experiments in argon with mica as dielectric showed strong argon excimer emission around wavelengths of $130 \mathrm{~nm}{ }^{6}$ The spectra, which were obtained with a spectral resolution of $2 \mathrm{~nm}$, showed features at $130 \mathrm{~nm}$, which indicated superimposed line radiation. The position of this line radiation in the spectrum pointed towards oxygen as impurity. Atomic oxygen is known to emit line radiation at around $130.4 \mathrm{~nm}$. These transitions are components of the $2 p^{4}{ }^{3} P \leftarrow 2 p^{3}\left({ }^{4} S^{0}\right) 3 s^{3} S^{0}$ triplet, at 130.2, 130.5 , and $130.6 \mathrm{~nm}$. Collisional dissociation of molecular oxygen in an argon discharge with added oxygen is expected to provide a high concentration of atomic oxygen. Resonant transfer of energy to the oxygen atom by the argon dimer, where the emission peaks at $130 \mathrm{~nm}$ is therefore likely. In order to study this effect we have measured the spectral emission of microhollow cathode discharges, and the spatial distribution of the VUV source in well defined argon/oxygen mixtures.

The electrode geometry of microhollow cathode discharges has been described in previous publications. ${ }^{1,2,6}$ In the present experiment we have used molybdenum electrodes with a thickness of $100 \mu \mathrm{m}$, separated by a $250 \mu \mathrm{m}$ layer alumina, and with circular holes of $100 \mu \mathrm{m}$ diameter drilled by means of an excimer laser through the three-layer structure. Alumina, rather than mica, as in previous experiments was used because of its tolerance to high temperature operation. The discharge was operated in a direct current mode, with sustaining voltages between 200 and $300 \mathrm{~V}$, and currents in the $2-10 \mathrm{~mA}$ range. The discharge gas was argon at high pressure, up to 1100 Torr, with admixtures of oxygen below $1 \%$. The discharge chamber was connected to a $0.2 \mathrm{~m}$ vacuum spectrograph (McPherson 302), and the spectra were recorded by means of a photomultiplier. The spatial distribution of the oxygen radiation source was obtained by using an optical imaging system including an image converter (Ropper Scientific ICCD-max), which converted the radiation (which passed through a filter with a peak transmission of $26.9 \%$ at $125.2 \mathrm{~nm}$ and a full width at half maximum of 17 $\mathrm{nm}$ ) into visible light. Absolute measurements of the radia- 


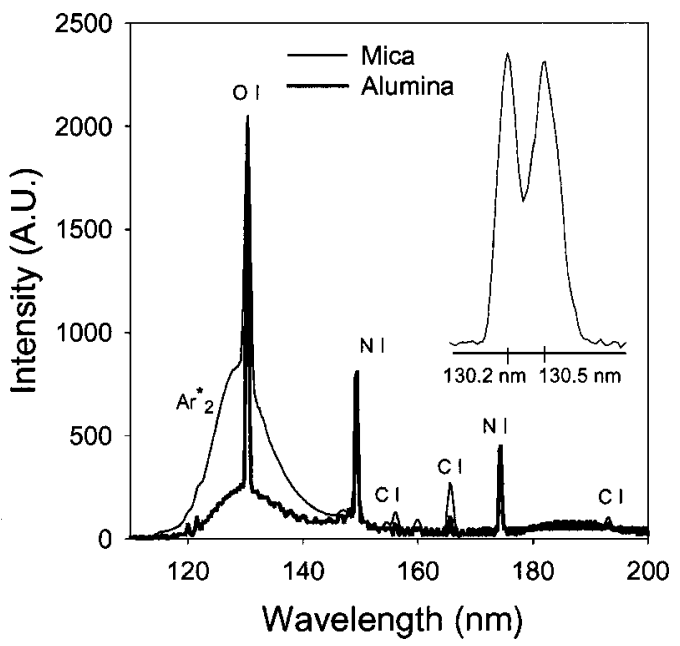

FIG. 1. Spectral emission of MHCDs in argon at a pressure of 830 Torr at a flow rate of $145 \mathrm{sccm}$, and at a current of $5 \mathrm{~mA}$ for two dielectric materials used as spacer between electrodes: mica and alumina. The insert shows atomic oxygen lines at 130.2 and $130.5 \mathrm{~nm}$.

tion were made by using the same spectral filter, and a diode (SXUV-100), where typical values of its sensitivity were provided by the manufacturer (International Radiation Detectors, Inc.).

Measurements of the spectral distribution in pure argon (research grade), after evacuating the discharge chamber to $10^{-4}$ Torr by means of a turbomolecular pump, revealed that even in this case impurities determined to a large extent the emission in the VUV range from 120 to $200 \mathrm{~nm}$. Figure 1 shows the emission spectra of argon MHCDs with mica and alumina as dielectrics. Whereas for mica, a natural material, the presence of impurities, such as oxygen, nitrogen, and particularly carbon is not surprising, the even stronger presence of nitrogen and oxygen with alumina as dielectric is unexpected. It is assumed that these gases were introduced during the laser drilling process which was performed in atmospheric air and is based on local melting and subsequent solidification at the edges of the hole. With alumina, line radiation at $130 \mathrm{~nm}$ contributed, even for pure argon filling, to approximately $20 \%$ of the total optical power in the range from 120 to $140 \mathrm{~nm}$. Spectra in a limited spectral range $(129-132 \mathrm{~nm})$ with the best spectral resolution, which we could obtain with our present diagnostic system $(\Delta \lambda \sim 0.2$ $\mathrm{nm}$ ) showed two peaks at 130.2 and $130.5 \mathrm{~nm}$, respectively (insert in Fig. 1). The second line profile is slightly asymmetric, indicating the presence of a third line. This spectrum therefore seems to correspond to the atomic oxygen transitions $2 p^{4}{ }^{3} P \leftarrow 2 p^{3}\left({ }^{4} S^{0}\right) 3 s^{3} S^{0}$ described in the introduction. The excitation of the oxygen triplet is assumed to be due to resonant energy transfer from $\mathrm{Ar}_{2}^{*}$ excimers with an energy in excess of $9.54 \mathrm{eV}$, corresponding to wavelengths shorter than $130.2 \mathrm{~nm}$, or possibly also from excited argon atoms at $13.2 \mathrm{eV}$, which serve as precursors for excimer formation.

The intensity of the oxygen impurity line does not depend on gas pressure as strongly as that of the nitrogen and carbon lines. This is shown in Fig. 2 (upper section) where the VUV spectrum of a MHCD in argon is shown for a pressure of 1100 Torr, rather than 830 Torr as in Fig. 1. With oxygen added to argon the intensity of the oxygen line emis-

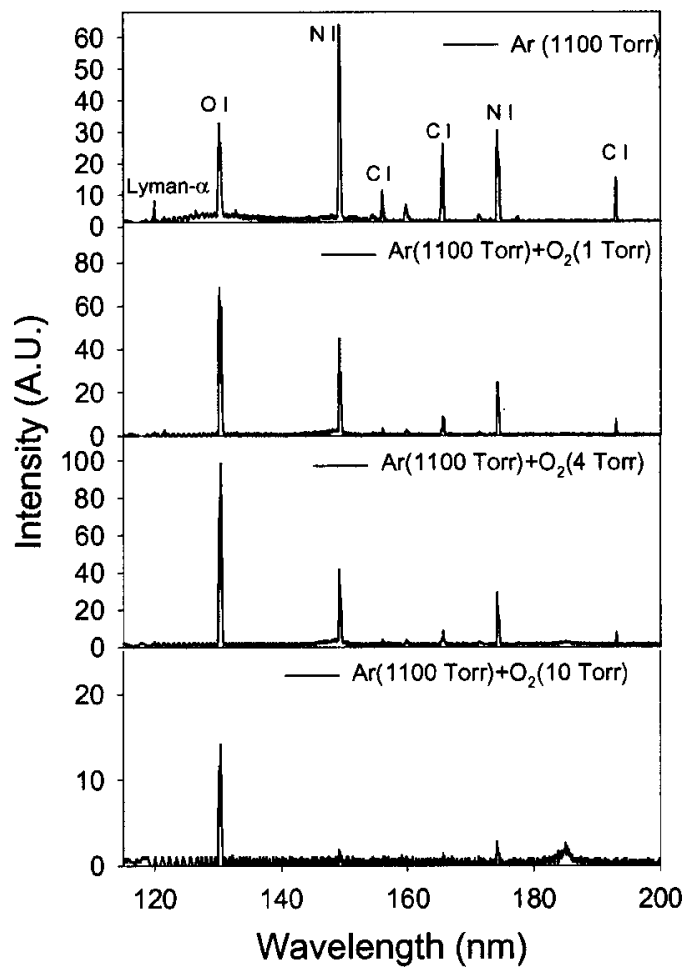

FIG. 2. Spectral emission of MHCDs in argon at 1100 Torr with increasing concentration of added oxygen. The oxygen lines at 130.2 and $130.5 \mathrm{~nm}$ reach a maximum intensity at 4 Torr of oxygen added to 1100 Torr of argon.

sion increases at the expense of the argon excimer emission (Fig. 2, lower sections). It reaches a maximum at approximately 4 Torr oxygen added to argon at 1100 Torr. With increasing oxygen concentration, not only the argon excimer radiation disappears, but also the other lines in the spectrum almost vanish. However, at an admixture of 10 Torr oxygen to the 1100 Torr argon, molecular oxygen emission at 185 $\mathrm{nm}$ begins to emerge. The studies on the effect of various concentrations of oxygen in argon at a given pressure were performed at a discharge current of $10 \mathrm{~mA}$. Reducing the current to the lowest possible current value of $2 \mathrm{~mA}$ (below that the discharge could not longer be sustained) for the same pressure showed a linear decrease in atomic oxygen emission with current.

Absolute measurements of the power emitted in the spectral range of interest, around $130 \mathrm{~nm}$, were performed by means of the semiconductor diode (SXUV-100). The diode which has an active area of $1 \mathrm{~cm}^{2}$ was placed at a distance of $1.6 \mathrm{~cm}$ in front of the discharge and the bandpass filter. The responsivity of the diode in the range from 120 to $140 \mathrm{~nm}$ is $0.01 \mathrm{~A} / \mathrm{W}$. Convoluting the emission spectra with the filter transmission and assuming that the emission is isotropic, the internal efficiency of the oxygen emitter was found to be $0.7 \%$ at oxygen concentrations of less than approximately $0.1 \%$ in argon (at 1100 Torr and a discharge current of 10 $\mathrm{mA})$. This corresponds to a total optical power of about 15 $\mathrm{mW}$ per microhollow cathode discharge in the spectral range covered by the optical filter. The efficiency decreases with increasing oxygen concentration, and for oxygen concentrations of $0.9 \%$ it is only $0.2 \%$. The sustaining discharge voltage increases with increasing oxygen concentration at constant current. For a $10 \mathrm{~mA}$ discharge, the sustaining voltage increases from $225 \mathrm{~V}$ for the case where no oxygen was 


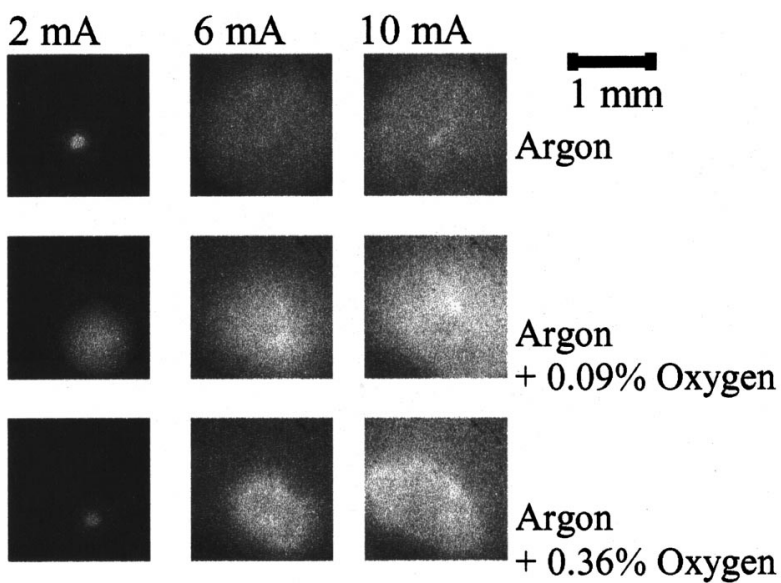

FIG. 3. Spatial distribution of the VUV source for different currents and argon-oxygen mixtures. The argon pressure was 1100 Torr. The size of the microhollow cathode opening is indicated by the circular luminous area in the upper left-hand photograph (argon, $2 \mathrm{~mA}$ ).

added to approximately $300 \mathrm{~V}$ for a $0.9 \%$ oxygen concentration.

The spatial distribution of the oxygen emission source at $130 \mathrm{~nm}$ was obtained by imaging the radiation source through the same spectral filter, which was used for absolute intensity measurements. The results are shown in Fig. 3 for three oxygen concentrations at three discharge currents. At lowest current $(2 \mathrm{~mA})$ the source is for the case that no oxygen is added and for high concentrations of oxygen $(0.36 \%)$ concentrated in the microhollow cathode. For oxygen concentrations between these two values, at $0.09 \%$, it extends even at low currents over an area several times the diameter of the cathode hole. The area of the VUV source increases with increasing current. However, whereas for the case with no oxygen added, this extension is symmetrical, for the case of $0.09 \%$ and even more for $0.36 \%$ oxygen added, it is inhomogeneous with irregular boundaries.

One application of this line radiation source could be advanced photolithography. Because of the small concentra- tion of oxygen in argon, the reabsorption of the $130.4 \mathrm{~nm}$ radiation in the gas mixture is presumably negligible for distances relevant for such an application, typically on the order of centimeter. The measured width of the oxygen lines is in our case determined by the resolution of our spectral system, which is approximately $0.2 \mathrm{~nm}$. However, for an application which depends on minimum spectral width for high resolution the width of the single line is not relevant, but the spectral width of the triplet, and this is at best $0.4 \mathrm{~nm}$. A way to reduce the spectral width further is by a more selective excitation of the components of the triplet. We have found, that with increasing oxygen concentration the transitions at 130.5 and $130.6 \mathrm{~nm}$ become more pronounced. The ratio of the two line intensities at 130.2 and $130.5 \mathrm{~nm}$ changes from 0.8 for no oxygen added, to 1.3 , when $0.9 \%$ oxygen was added to the argon. Increasing the concentration further, beyond the $1 \%$ range might enhance this effect, which is not understood at this time, but at the expense of efficiency. Other ways to obtain smaller line width is to look for other gases with conceivable resonant energy transfer in the argon excimer emission region, such as nitrogen, krypton and xenon. Another advantage of MHCDs as VUV radiation sources is based on the possibility to form arrays of these point sources. ${ }^{7}$ This allows us to generate extended area light sources where the radiant emittance can be controlled by adjusting the current through individual MHCDs.

This work was supported by the National Science Foundation (NSF).

${ }^{1}$ K. H. Schoenbach, A. El-Habachi, W. Shi, and M. Ciocca, Plasma Sources Sci. Technol. 6, 468 (1997).

${ }^{2}$ A. El-Habachi and K. H. Schoenbach, Appl. Phys. Lett. 73, 885 (1998).

${ }^{3}$ P. Kurunczi, H. Shah, and K. Becker, J. Phys. B 32, 651 (1999).

${ }^{4}$ P. Kurunczi, J. Lopez, H. Shah, and K. Becker, Int. J. Mass Spectrom. (in press).

${ }^{5}$ J. Wieser, M. Salvermoser, L. H. Shaw, A. Ulrich, D. E. Murnick, and H. Dahi, J. Phys. B 31, 4589 (1998).

${ }^{6}$ A. El-Habachi and K. H. Schoenbach, Appl. Phys. Lett. 72, 22 (1998).

${ }^{7}$ W. Shi, R. H. Stark, and K. H. Schoenbach, IEEE Trans. Plasma Sci. 27, 16 (1999). 